\title{
MODUL NEUTROSOFIK KUAT
}

\author{
Suryoto $^{1}$, Harjito $^{2}$ dan Titi Udjiani ${ }^{3}$ \\ ${ }^{1,2,3}$ Kelompok Bidang Keahlian (KBK) Aljabar Departemen Matematika \\ Fakultas Sains dan Matematika, Universitas Diponegoro Semarang \\ Email : ${ }^{1}$ suryotomath@gmail.com, ${ }^{2}$ harjito@gmail.com, ${ }^{3}$ udjianititi@yahoo.com
}

\begin{abstract}
Given any neutrosophic ring with unity and a commutatively additive neutrosophic group. Then we can formed a neutrosophic algebraic structure is called a strong neutrosphic module. From the concept of weak neutrosophic module we extend to the concept of strong neutrosophic module. In this paper, also elementary properties of strong neutrosophic module are given.
\end{abstract}

Keywords: commutative neutrosophic group, neutrosophic ring with unity, weak neutrosophic module, strong neutrosophic module

\begin{abstract}
Abstrak. Diberikan sebarang ring neutrosofik dengan satuan dan sebuah grup neutrosofik aditif komutatif. Telah di bentuk suatu struktur aljabar neutrosofik yang disebut modul neutrosofik kuat. Dari konsep modul neutrosofik lemah, telah dikembangkan konsep modul neutrosofik kuat. Diberikan juga sifat-sifat dasar dari modul neutrosofik kuat dalam artikel ini.
\end{abstract}

Keywords: Grup neutrosofik komutatif,, ring neutrosofik dengan satuan, modul neutrosofik lemah, modul neutrosofik kuat

\section{PENDAHULUAN}

Dalam membahas struktur modul neutrosofik kuat dan sifat-sifat utamanya, terlebih dahulu diperlukan konsep neutrosofik ring dengan elemen satuan. Menurut [1], neutrosofik ring dari suatu ring klasik merupakan ring dan struktur neutrosofik ini senantiasa memuat himpunan bagian sejati yang merupakan ring, yaitu ring dasar pembentuknya. Dalam hal ini, neutrosofik ring yang mempunyai struktur ring, penulis mengatakan neutrosofik ringnya sebagai ring neutrosofik.

Selain itu pada [2] telah diberikan konsep modul neutrosofik (juga modul neutrosofik kiri maupun kanan), yang didefinisikan atas ring (klasik) komutatif dengan elemen satuan. Dalam hal ini, penulis menyebut modul neutrosofik yang terbentuk dengan istilah modul neutrosofik lemah. Pada [3] dan [4] diberikan beberapa sifat dasar dari struktur modul neutrosofik lemah tersebut. Dari struktur modul neutrosofik lemah ini, dengan memperluas ring dasar pembentuknya (ring klasik) menjadi ring neutrosofik diperoleh modul neutrosofik yang lebih umum, atau yang dikenal dengan modul neutrosofik kuat.

Disamping struktur aljabar modul neutrosofik lemah, pada artikel ini juga diberikan atau diulas kembali tentang pengertian elemen neutrosofik yang merupakan elemen penting dalam pembentukan struktur modul neutrosofik kuat pada khususnya dan struktur aljabar neutrosofik pada umumnya. Pada [1] juga diberikan pengertian elemen neutrosofik sebagai 
elemen yang dapat dipandang sebagai suatu indeterminate dan bersifat idempoten terhadap operasi perkalian secara umum. Untuk mempelajari elemen neutrosofik ini dan juga beberapa struktur aljabar neutrosofik yang dapat dibentuk darinya, pembaca dapat melihat pada referensi [5], [6], dan [7].

\section{NEUTROSOFIK MODUL LEMAH DAN ASPEK ALJABAR YANG TERKAIT}

Pengkajian modul neutrosofik (lemah) tidak terlepas dari peran struktur grup aditif neutrosofik yang bersifat komutatif sebagai salah satu komponen pembentuknya, selain ring klasik dengan elemen satuan. Sebagai awal pembahasan struktur neutrosofik, diberikan kembali pengertian elemen neutrosofik sebagai dasar pembentukan struktur neutrosofik pada umumnya.

Menurut [1], elemen neutrosofik dapat dipandang sebagai suatu indeterminate dan elemen ini bersifat idempoten terhadap operasi perkalian secara umum. Elemen ini dinotasikan dengan $I$, dengan maksud untuk membedakan dengan notasi $i$ yang menyatakan satuan imajiner pada himpunan semua bilangan kompleks yang bersifat $i^{2}=-1$. Sedangkan elemen neutrosofik bersifat $I \cdot I=I^{2}=I$.

Berikut ini diberikan definisi struktur neutrosofik grup yang dapat dibentuk dari sebarang grup dan elemen neutrosofik sebagai dasar pembentukan modul neutrosofik lemah.

Definisi 1 [6] Misalkan $G=\langle G, *\rangle$ sebarang grup, neutrosofik grup yang dibangun oleh grup $G$ dan elemen neutrosofik I terhadap operasi * dinotasikan dengan $N(G)=\{\langle G \cup I\rangle, *\}$, dimana $\langle G \cup I\rangle=\{a * b I: a, b \in G\}$.

Selanjutnya diberikan beberapa contoh neutrosofik grup yang merupakan grup dan bukan grup, seperti diberikan pada dua contoh berikut.

Contoh 1 Pandang himpunan semua bilangan bulat modulo $5, \mathbb{Z}_{5}=\{\overline{0}, \overline{1}, \overline{2}, \overline{3}, \overline{4}\}$, terhadap operasi “ $+_{5}$ ” atau penjumlahan modulo $5, \mathbb{Z}_{5}=\left(\mathbb{Z}_{5},+_{5}\right)$ membentuk grup aditif. Neutrosofik dari grup $\mathbb{Z}_{5}$ ini adalah $N\left(\mathbb{Z}_{5}\right)=\left\{\left\langle\mathbb{Z}_{5} \cup I\right\rangle,{ }_{5}\right\}$ yang juga merupakan grup terhadap operasi penjumlahan modulo 5 .

Contoh 2 Pandang himpunan $G=\mathbb{Z}_{7} \backslash\{\overline{0}\}$, maka $G$ merupakan grup terhadap operasi perkalian modulo 7. Himpunan $N(G)=\left\{\langle G \cup I\rangle, \bullet_{7}\right\}$ adalah neutrosofik grup yang dibentuk oleh grup $G$ dan elemen neutrosofik $I$. Tampak bahwa $N(G)$ bukan grup, karena elemen neutrosofik $I$ bukan elemen satuan dan hanya suatu indeterminate, sehingga elemen ini tidak mempunyai invers perkalian.

Dari contoh-contoh tersebut diperoleh sifat penting terkait dengan struktur neutrosofik dari suatu grup, seperti dinyatakan dalam teorema di bawah ini. 
Teorema 1 [1] Diberikan sebarang grup $G=\langle G, *\rangle$ dan $N(G)=\{\langle G \cup I\rangle, *\}$ adalah neutrosofik grup dari grup $G$, maka berlaku

1. Pada umumnya $N(G)$ bukan grup

2. $N(G)$ senantiasa memuat suatu grup

Bukti : Untuk memperlihatkan bahwa neutrosofik grup $N(G)$ pada umumnya bukan merupakan grup, cukup dipandang Contoh 2, yaitu

$$
\left\langle\left(\mathbb{Z}_{7} \backslash\{\overline{0}\}\right) \cup I\right\rangle
$$

bukan merupakan grup terhadap operasi perkalian modulo 7, meskipun himpunan

$$
\mathbb{Z}_{7} \backslash\{\overline{0}\}=\{\overline{1}, \overline{2}, \overline{3}, \overline{4}, \overline{5}, \overline{6}\}
$$

membentuk grup multiplikatif di bawah operasi " $\bullet_{7}$ ".

Selanjutnya untuk bukti bagian kedua, karena grup $G$ dan elemen neutrosofik $I$ adalah komponen pembentuk neutrosofik grup $N(G)=\{\langle G \cup I\rangle, *\}$, maka tampak bahwa $G \subset N(G)$, yaitu neutrosofik grup $N(G)$ senantiasa memuat suatu grup.

Selanjutnya diberikan definisi grup neutrosofik komutatif.

Definisi 2 [6] Misalkan $N(G)=\{\langle G \cup I\rangle$,*\} sebarang grup neutrosofik. Grup neutrosofik $N(G)$ dikatakan komutatif jika untuk setiap $x, y \in N(G)$ berlaku $x * y=y * x$.

Setelah diberikan konsep grup neutrosofik, sebagai salah satu pilar utama dalam pembentukan struktur modul neutrosofik, berikut diberikan beberapa definisi dan juga sifat utama dari struktur neutrosofik ring sebagai komponen lain yang ikut berperan pada pembentukan struktur modul neutrosofik kuat.

Definisi 3 [1] Misalkan $R=(R,+, \bullet)$ sebarang ring, maka himpunan

$$
\langle R \cup I\rangle=\{a+b I: a, b \in R\}
$$

dinamakan neutrosofik ring yang dibangun oleh $R$ dan I dibawah operasi dari $R$.

Berikut ini adalah contoh-contoh neutrosofik ring dari struktur ring klasik yang sudah sangat dikenal.

Contoh 3 Himpunan $\left\langle\mathbb{Z}_{n} \cup I\right\rangle$, dengan $n$ bilangan bulat dan $n \geq 2$, merupakan neutrosofik ring bilangan bulat modulo $n$.

Contoh 4 Himpunan matriks

$$
\left\langle M_{2 \times 2} \cup I\right\rangle=\left\{\left[\begin{array}{ll}
p & q \\
r & s
\end{array}\right]: p, q, r, s \in\left(\left\langle\mathbb{Z}_{3} \cup I\right\rangle,+_{3}\right)\right\}
$$


adalah neutrosofik ring dari ring matriks berukuran $2 \times 2$ dengan entri-entrinya merupakan anggota himpunan

$$
\left\langle\mathbb{Z}_{3} \cup I\right\rangle=\{\overline{0}, \overline{1}, \overline{2}, I, \overline{2} I, \overline{1}+I, \overline{2}+I, \overline{1}+\overline{2} I, \overline{2}+\overline{2} I\} .
$$

Selanjutnya diberikan struktur aljabar dari neutrosofik ring dari suatu ring.

Teorema 2 Jika $\langle R \cup I\rangle$ neutrosofik ring dari ring $R$, maka berlaku

1. $\langle R \cup I\rangle$ membentuk ring terhadap operasi yang sama pada ring $R$ dan

2. $R \underset{\neq}{R}\langle R \cup I\rangle$, dengan $R$ ring.

Bukti : Untuk bagian pertama, bukti selengkapnya diberikan oleh [1] halaman 32-33, sedangkan untuk bukti bagian keduanya langsung dari kenyataan bahwa senantiasa berlaku $R \subset\langle R \cup I\rangle$.

Seperti sudah dinyatakan pada bagian Pendahuluan dan hasil dari Teorema 2 bagian (1) tersebut, karena neutrosofik ring senantiasa merupakan ring maka penulis mengatakan neutrosofik ring dengan istilah ring neutrosofik.

Definisi berikut memberikan beberapa jenis ring neutrosofik dari suatu ring.

Definisi 4 [2] Misalkan $\langle R \cup I\rangle$ suatu ring neutrosofik, ring neutrosofik $\langle R \cup I\rangle$ dikatakan komutatif jika untuk sebarang $a, b \in\langle R \cup I\rangle$ maka $a b=b a$. Lebih lanjut, jika terdapat elemen $1=1+0 I \in\langle R \cup I\rangle$ sedemikian hingga $1 \cdot r=r=r \cdot 1$ untuk setiap $r \in\langle R \cup I\rangle$, maka dikatakan $\langle R \cup I\rangle$ adalah ring neutosofik komutatif dengan elemen satuan.

Selanjutnya diberikan definisi terkait dengan struktur modul neutrosofik lemah, seperti dituangkan ke dalam beberapa definisi berikut.

Definisi 5 [2, 3] Misalkan $R=(R,+, \bullet)$ ring dengan elemen satuan 1. Suatu modul kiri neutrosofik atas ring $R$ adalah grup neutrosofik komutatif $(\langle M \cup I\rangle,+)$ yang dilengkapi dengan operasi perkalian skalar $:: R \times\langle M \cup I\rangle \rightarrow\langle M \cup I\rangle$ dan memenuhi kondisi-kondisi berikut :
a. $\alpha(x+y)=\alpha x+\alpha y$
b. $(\alpha+\beta) x=\alpha x+\beta x$
c. $(\alpha \beta) x=\alpha(\beta x)$
d. $1 x=x$

untuk setiap $\alpha, \beta \in R$ dan $x, y \in\langle M \cup I\rangle$. 
Sementara itu untuk definisi modul kanan neutrosofik dapat didefinisikan analog, perbedaannya terletak pada operasi perkalian skalarnya, dimana tindakan ring $R$ terhadap himpunan $\langle M \cup I\rangle$-nya beraksi dari sebelah kanan untuk mendapatkan elemen di grup neutrosofik komutatif $\langle M \cup I\rangle$. Dengan demikian definisi untuk modul kanan neutrosofik menjadi :

Definisi $6[2,3]$ Misalkan $R=(R,+, \bullet)$ ring dengan elemen satuan 1. Suatu modul kanan neutrosofik atas ring $R$ adalah grup neutrosofik komutatif $(\langle M \cup I\rangle,+)$ yang dilengkapi dengan operasi perkalian skalar $\cdot:\langle M \cup I\rangle \times R \rightarrow\langle M \cup I\rangle$ dan memenuhi kondisi-kondisi berikut :
a. $(x+y) \alpha=x \alpha+y \alpha$
b. $x(\alpha+\beta)=x \alpha+x \beta$
c. $x(\alpha \beta)=(x \alpha) \beta$
d. $x 1=x$

untuk setiap $\alpha, \beta \in R$ dan $x, y \in\langle M \cup I\rangle$.

Dalam hal ring $R$ merupakan ring komutatif, pengertian modul kiri neutrosofik atas $R$ dan modul kanan neutrosofik atas $R$ adalah identik. Selanjutnya jika $\langle M \cup I\rangle$ merupakan modul kiri neutrosofik dan sekaligus modul kanan neutrosofik atas $R$, maka $\langle M \cup I\rangle$ disebut modul neutrosofik atas $R$ atau $R$-modul neutrosofik atau dapat dikatakan $\langle M \cup I\rangle$ merupakan modul neutrosofik lemah.

Untuk memperjelas pengertian modul neutrosofik lemah ini telah diberikan contoh pada [3], yaitu bahwa grup neutrosofik komutatif $\left(\left\langle\mathbb{Z}_{n} \cup I\right\rangle,+\right)$, dengan $n$ suatu bilangan bulat merupakan $\mathbb{Z}$-modul neutrosofik dengan definisi operasi perkalian skalar

$$
f: \mathbb{Z} \times\left\langle\mathbb{Z}_{n} \cup I\right\rangle \rightarrow\left\langle\mathbb{Z}_{n} \cup I\right\rangle
$$

dengan $f(m, \bar{n})=\overline{m n}$, untuk setiap $m \in \mathbb{Z}$ dan $\bar{n} \in\left\langle\mathbb{Z}_{n} \cup I\right\rangle$.

Berikut ini diberikan sifat penting dari modul neutrosofik lemah dalam kaitannya dengan struktur modul klasik atas suatu ring.

Teorema 3 Setiap modul neutrosofik lemah adalah modul klasik.

Bukti : Misalkan $\langle M \cup I\rangle$ adalah modul neutrosofik lemah atau $\langle M \cup I\rangle$ suatu $R$-modul neutrosofik, maka $(\langle M \cup I\rangle,+)$ adalah grup neutrosofik komutatif. Diambil sebarang elemen $\alpha, \beta \in R$ dan $x=p+q I, y=r+s I \in\langle M \cup I\rangle$ serta tanpa mengurangi keumuman bukti 
misalkan tindakan dari ring $R$ beraksi dari kanan pada grup neutrosofik $\langle M \cup I\rangle$. Dengan demikian diperoleh

1. $(x+y) \alpha=[(p+q I)+(r+s I)] \alpha=(p+q I+r+s I) \alpha$

$$
=p \alpha+q \alpha I+r \alpha+s \alpha I=(p+q I) \alpha+(r+s I) \alpha=x \alpha+y \alpha
$$

2. $x(\alpha+\beta)=(p+q I)(\alpha+\beta)=p \alpha+q \alpha I+p \beta+q \beta I$

$$
=(p+q I) \alpha+(p+q I) \beta=x \alpha+x \beta
$$

3. $x(\alpha \beta)=(p+q I)(\alpha \beta)=p \alpha \beta+q \alpha \beta I=(p \alpha) \beta+(q \alpha I) \beta$

$$
=(p \alpha+q \alpha I) \beta=[(p+q I) \alpha] \beta=(x \alpha) \beta
$$

4. $x \cdot 1=(p+q I) \cdot 1=p+q I=x$

Ini memperlihatkan bahwa $\langle M \cup I\rangle$ merupakan modul (klasik) atas ring $R$.

\section{MODUL NEUTROSOFIK KUAT DAN SIFAT-SIFATNYA}

Pada bagian ini diberikan definisi dan sifat-sifat yang berlaku pada modul neutrosofik kuat. Pada bagian sebelumnya, jika ring dasar pembentuk modul neutrosofiknya diperluas menjadi ring neutrosofik, setidaknya neutrosofik ring dari ring klasiknya, diperoleh konsep modul kiri neutrosofik kuat, modul kanan neutrosofik kuat, dan modul neutrosofik kuat. Berikut adalah definisi yang dimaksudkan.

Definisi 7 Misalkan $R=(R,+, \cdot)$ ring dengan elemen satuan 1 dan $\langle R \cup I\rangle$ ring neutrosofik dari ring $R$. Suatu modul kiri neutrosofik atas ring neutrosofik $\langle R \cup I\rangle$ adalah grup neutrosofik komutatif $(\langle M \cup I\rangle,+)$ yang dilengkapi dengan operasi perkalian skalar $\cdot:\langle R \cup I\rangle \times\langle M \cup I\rangle \rightarrow\langle M \cup I\rangle$ dan memenuhi kondisi-kondisi berikut :
a. $\alpha(m+n)=\alpha m+\alpha n$
b. $(\alpha+\beta) m=\alpha m+\beta m$
c. $(\alpha \beta) m=\alpha(\beta m)$
d. $1 m=m$

untuk setiap $\alpha, \beta \in\langle R \cup I\rangle$ dan $m, n \in\langle M \cup I\rangle$.

Sementara itu untuk definisi modul kanan neutrosofik atas ring neutrosofik $\langle R \cup I\rangle$ dapat didefinisikan secara analog, perbedaannya terletak pada tindakan ring neutrosofik $\langle R \cup I\rangle$ terhadap grup neutrosofik komutatif $\langle M \cup I\rangle$-nya sehingga diperoleh definisi berikut. 
Definisi 8 Misalkan $R=(R,+, \bullet)$ ring dengan elemen satuan 1 dan $\langle R \cup I\rangle$ ring neutrosofik dari ring $R$. Suatu modul kanan neutrosofik atas ring neutrosofik $\langle R \cup I\rangle$ adalah grup neutrosofik komutatif $(\langle M \cup I\rangle,+)$ yang dilengkapi dengan operasi perkalian skalar $\cdot:\langle M \cup I\rangle \times\langle R \cup I\rangle \rightarrow\langle M \cup I\rangle$ dan memenuhi kondisi-kondisi berikut :
a. $(m+n) \alpha=m \alpha+n \alpha$
b. $m(\alpha+\beta)=m \alpha+m \beta$
c. $m(\alpha \beta)=(m \alpha) \beta$
d. $m 1=m$

untuk setiap $\alpha, \beta \in\langle R \cup I\rangle$ dan $m, n \in\langle M \cup I\rangle$.

Dalam hal ring $R$ merupakan ring komutatif yang berakibat ring neutrosofik $\langle R \cup I\rangle$ juga merupakan ring komutatif, pengertian modul kiri neutrosofik dan modul kanan neutrosofik atas ring neutrosofik $\langle R \cup I\rangle$ adalah identik. Selanjutnya jika $\langle M \cup I\rangle$ merupakan modul kiri neutrosofik dan sekaligus modul kanan neutrosofik atas $\langle R \cup I\rangle$, maka $\langle M \cup I\rangle$ dikatakan modul neutrosofik atas $\langle R \cup I\rangle$ atau disebut juga $\langle R \cup I\rangle$-modul neutrosofik atau dapat dikatakan $\langle M \cup I\rangle$ merupakan modul neutrosofik kuat. Istilah kuat ini merujuk pada ring neutrosofik $\langle R \cup I\rangle$ sebagai ring dasar pembentuk modul neutrosofiknya.

Berikut ini diberikan beberapa contoh modul neutrosofik lemah yang sekaligus juga merupakan modul neutrosofik kuat.

Contoh 3 Dari ring bilangan bulat $\mathbb{Z}=(\mathbb{Z},+, \bullet)$, diperoleh bahwa grup neutrosofik komutatif $(\langle\mathbb{Z} \cup I\rangle,+)$ adalah modul neutrosofik lemah atas ring $\mathbb{Z}$ dan sekaligus merupakan modul neutrosofik kuat atas neutrosofik ring $\langle\mathbb{Z} \cup I\rangle$.

Contoh 4 Grup neutrosofik komutatif $\left(\left\langle M_{2 \times 2}(\mathbb{Q}) \cup I\right\rangle,+\right)$, dengan

$$
M_{2 \times 2}=\left\{\left[\begin{array}{ll}
p & q \\
r & s
\end{array}\right]: p, q, r, s \in\langle\mathbb{Q} \cup I\rangle\right\}
$$

merupakan modul neutrosofik lemah atas ring bilangan rasional $\mathbb{Q}$ dan merupakan modul neutrosofik kuat atas neutrosofik ring $\langle\mathbb{Q} \cup I\rangle$.

Berikut ini diberikan hubungan antara struktur modul neutrosofik kuat dengan struktur modul neutrosofik lemah dan struktur modul klasik atas ring maupun atas ring neutrosofik, seperti dituangkan dalam dua teorema berikut. 
Teorema 4 Setiap modul neutrosofik kuat adalah modul neutrosofik lemah.

Bukti: Misalkan $(\langle M \cup I\rangle,+)$ adalah sebarang $\langle R \cup I\rangle$-modul neutrosofik atau modul neutrosofik kuat. Karena senantiasa berlaku $R \underset{\neq}{\not}\langle R \cup I\rangle$, untuk setiap ring $R=(R,+, \bullet)$, maka $(\langle M \cup I\rangle,+)$ merupakan modul neutrosofik atas ring $R$ atau $\langle M \cup I\rangle$ merupakan modul neutrosofik lemah.

Teorema 5 Setiap modul neutrosofik kuat adalah modul klasik atas ring neutrosofik.

Bukti : Tanpa mengurangi keumuman bukti, misalkan $\langle M \cup I\rangle$ merupakan modul neutrosofik kuat atas ring neutrosofik $\langle R \cup I\rangle$ dan tindakan ring neutrosofik $\langle R \cup I\rangle$ beraksi dari kiri pada $\langle M \cup I\rangle$, maka $(\langle M \cup I\rangle,+)$ adalah grup neutrosofik komutatif. Diambil sebarang $\quad \alpha=a+b I, \beta=c+d I \in\langle R \cup I\rangle$ dan $m=p+q I, n=r+s I \in\langle M \cup I\rangle$, dengan $p, q, r, s \in M$ dan $a, b, c, d \in R$, maka diperoleh

1. $\alpha(m+n)=(a+b I)[(p+q I)+(r+s I)]=(a+b I)(p+q I+r+s I)$

$$
\begin{aligned}
& =(a p+a r)(a q+a s+b p+b q+b r+b s) I \\
& =(a p+a q I+b p I+b q I)+(a r+a s I+b r I+b s I) \\
& =(a+b I)(p+q I)+(a+b I)(r+s I)=\alpha m+\beta m
\end{aligned}
$$

2. $(\alpha+\beta) m=[(a+b I)+(c+d I)](p+q I)=(a+b I+c+d I)(p+q I)$

$$
\begin{aligned}
& =(a p+c q)(a q+c q+b p+d p+b q+d q) I \\
& =(a p+a q I+b p I+b q I)+(c p+c q I+d p I+d q I) \\
& =(a+b I)(p+q I)+(c+d I)(p+q I)=\alpha m+\beta m
\end{aligned}
$$

3. $(\alpha \beta) m=[(a+b I)(c+d I)](p+q I)=(a c+a d I+b c I+b d I)(p+q I)$

$$
\begin{aligned}
& =a c p+(a c q+a d p+a d q+b c p+b c q+b d p+b d q) I \\
& =a(c p+c q I+d p I+d q I)+b I(c p+c q I+d p I+d q I) \\
& =(a+b I)(c p+c q I+d p I+d q I) \\
& =(a+b I)[(c+d I)(p+q I)]=\alpha(\beta m)
\end{aligned}
$$

4. Untuk $1=1+0 I \in\langle R \cup I\rangle$ diperoleh

$$
1 m=(1+0 I)(p+q I)=p+(q+0+0) I=p+q I=m \text {. }
$$

Dengan demikian dari ke-empat hasil tersebut dan mengingat $R \subset \underset{\neq}{ }\langle R \cup I\rangle$ dengan $R$ suatu ring, maka terbukti bahwa $\langle M \cup I\rangle$ merupakan modul (klasik) atas ring $R$. 
Selanjutnya diberikan sifat penting dari modul neutrosofik kuat, seperti dinyatakan dalam teorema berikut ini.

Teorema 6 Misalkan $\langle M \cup I\rangle$ adalah modul neutrosofik kuat atas ring neutrosofik $\langle R \cup I\rangle$, maka berlaku

1. Jika $m+n_{1}=m+n_{2}$, maka $n_{1}=n_{2}$

2. $\alpha 0=0$

3. $0 m=0$

4. $(-\alpha) m=\alpha(-m)=-(\alpha m)$

untuk setiap $m, n_{1}, n_{2} \in\langle M \cup I\rangle$ dan $\alpha \in\langle R \cup I\rangle$.

Bukti : Diambil sebarang $m=p+q I, n_{1}=r_{1}+s_{1}, n_{2}=r_{2}+s_{2} I \in\langle M \cup I\rangle$ dan sebarang skalar $\alpha=a+b I \in\langle R \cup I\rangle$, maka diperoleh

1. $m+n_{1}=m+n_{2} \Leftrightarrow(p+q I)+\left(r_{1}+s_{1} I\right)=(p+q I)+\left(r_{2}+s_{2} I\right)$

$$
\begin{aligned}
& \Leftrightarrow(-p-q I)+(p+q I)+\left(r_{1}+s_{1} I\right)=(-p-q I)+(p+q I)+\left(r_{2}+s_{2} I\right) \\
& \Leftrightarrow(0+0 I)+\left(r_{1}+s_{1} I\right)=(0+0 I)+\left(r_{2}+s_{2} I\right) \Leftrightarrow r_{1}+s_{1} I=r_{2}+s_{2} I \\
& \Leftrightarrow n_{1}=n_{2}
\end{aligned}
$$

2. Mengingat $0=0+0 I \in\langle M \cup I\rangle$, maka

$$
\alpha 0=(a+b I)(0+0 I)=0+(0+0+0) I=0+0 I=0
$$

3. Karena $0=0+0 I \in\langle R \cup I\rangle$, maka

$$
0 m=(0+0 I)(p+q I)=0+(0+0+0) I=0+0 I=0
$$

4. $(-\alpha) m=(-a-b I)(p+q I)=-a p+(-a q-b p-b q) I=-[a p+(a q+b p+b q) I]$

$$
=-[(a+b I)(p+q I)]=-(\alpha m)
$$

Demikian pula $(-\alpha) m=\alpha(-1) m=\alpha(-m)$.

\section{KESIMPULAN}

Dari pembahasan sebelumnya didapat kesimpulan: setiap modul neutrosopik kuat senantiasa merupakan modul neutrosofik lemah, tetapi tidak berlaku sebaliknya. Demikian juga dapat diperlihatkan bahwa setiap modul neutrosofik lemah (kuat) senantiasa merupakan modul klasik atas ring pembangun neutrosofik ringnya (atau modul klasik atas ring neutrosofiknya). 


\section{REFERENSI}

[1] W.B.V. Kandasamy and F. Smarandache, "Neutrosophic rings", Hexis, Phoenix, Arizona, 2006.

[2] A.A.A. Agboola, A.D. Akinola and O.Y. Oyebola, "Neutrosophic rings I", Int. J. Math. Comb., vol. 4, pp. 1-14, 2011.

[3] Suryoto, B. Irawanto, dan N.P. Puspita, "Neutrosofik modul dan sifat-sifatnya", $J$. Matematika, vol. 18, no. 1, pp. 30-35, 2015.

[4] Suryoto, B. Irawanto, dan N.P. Puspita, "Sifat-sifat lanjut neutrosofik modul", $J$. Matematika, vol. 19, no. 2, pp. 78-86, 2016.

[5] W.B.V. Kandasamy and F. Smarandache, "Basic neutrosophic algebraic structures and their applications to fuzzy and neutrosophic models", Hexis, Church Rock, 2004.

[6] W.B.V. Kandasamy and F. Smarandache, "Some neutrosophic algebraic structures and neutrosophic n-algebraic structures", Hexis, Phoenix, Arizona, 2006.

[7] A.A.A. Agboola, E.O. Adeleke and S.A. Akinleye, "Neutrosophic rings II", Int. J. Math. Comb., vol. 2, pp. 1-8, 2012. 